ance of genetics for the study of cancer need not lead to any decision on this point.

To sum up, we can devise conditions under which either nature or nurture will play a pre-. dominant part in determining the incidence of cancer. Neither factor can possibly be neglected in a comprehensive survey. Except in a few cases, such as retinoblastoma, our knowledge is not sufficient to warrant interference with human breeding on eugenic grounds. Nevertheless, it is probable that in the ultimate solution of the problem of human cancer, eugenical measures will play their part.

1 Cloudman, A. M., Amer. J. Cancer, 16, 568; 1032.

- Bittner, J. J., Amer. J Cancer, 15, 2202; 1931

Lynch, C. J., J. Exp. Med., 48, 917 ; 1927.

- Curtis, Junning and Bullock, Amer. Nat., 87, 73; 1933.

- Murray, W. S., Science, 75, 640; 1932.

- Zavadskaia, J. Genetics, 27, 181; 1933.

\title{
Gem Stones*
}

\section{By Prof. W. T. Gordon}

$\mathrm{T}$ HE first essential of a gem is that it should be beautiful and attractive, but if the beauty be ephemeral the gem will not command continued popularity. Occasionally an attractive colour in 8 material will assume a paler tint, or vanish entirely, or even change to an opaque black shade. Or again, the surface may tarnish and all its beauty disappear. Change of colour, however, is not the only factor that may mar the glory of a beautiful substance. Lack of resistance to wear is very undesirable, particularly in transparent materials, and not all beautifully coloured minerals have the property of durability.

There is also a psychological factor that must not be omitted. Unless the material is rare it is little prized. Beauty therefore has to be accompanied by durability and rarity before popular opinion will consent to apply the term gem stone to any substance. The artistic and educated mind may resent this attitude, but vox populi is in this connexion vox dei, so far as monetary values and general acceptance of the term are concerned.

At the moment, however, beauty will be considered paramount, and there are several natural minerals that come into the category of gem stones. The methods adopted to display the maximum beauty are based on scientific principles, although these were nearly all discovered by the lapidary through experience, before they were formulated by the man of science. It is these laws and the methods adopted by the lapidary to secure their operation that will be considered here.

The natural minerals classed as gem stones may be opaque, translucent or transparent, and do not belong to any special category so far as their chemical composition is concerned : while one and the same material may occur in a great variety of colour and many degrees of transparency.

It seems probable that the earliest gems were attractively coloured substances with some degrce of lustre, that property depending on the intensity of the light reflected from the surface. Were that surface smoothed and polished, the lustre would be increased and the full value of the colour

- Friday evening discourse delivered at the Royal Institution on May 12. developed. As large continuous areas give the finest effects, curved surfaces were worked on the materials in order that the colour and lustre might be visible from any angle. The term cabochon is applied to this style of cutting, and the cabochon may be deep or shallow. When deep, the top surface may be ellipsoidal (oblate or of revolution) and is often called tallow-topped; when shallow, this term is not applied. 'The stone may have a flat base, a rounded base or a hollow base, and these styles are called cabochon, double cabochon, and hollow cabochon respectively. When the colour is deep and the material translucent, a hollow cabochon specimen is frequently lined with gold or silver foil on the hollow side, and the colour is much enhanced by light reflected through the stone, from the bright metal surface on the base.

Another class of gems, both opaque and translucent, exhibits a fibrous habit or has inclusions or even cavities, arranged in parallel series. If the fibres, inclusions or cavities are very delicate, and are set parallel to definite directions, light is reflected more intensely from the long edges of these, and a luminous zone or set of intersecting luminous zones is produced. Along with the natural colour of the material these bands of light produce an attractive appearance. Such stones are also cut in a rounded or oval form, and are termed cat's-eyes or star-stones according as there is one luminous band or three intersecting bands.

'Thus far the only scientific principles involved have been the formation of smooth, rounded shapes that will function in the reflection of light coming from any direction; and the larger the surface the better the effect.

The finest results of the lapidary's skill are seen, however, in the treatment of transparent gems, coloured or uncoloured, and the latter illustrate in the highest degree the skilful application of the principles of the refraction, reflection, dispersion and interference of light.

In coloured gems the beauty lies largely in that colour, whether the material be transparent or opaque; but, in colourless stones, the beauty must be developed by the skill of the artificer. A 
caste of colour in water-clear stones is a great blemish, for there is considerable absorption of light and consequently a loss in brilliancy. While, therefore, a distinctive colour may be tolerated or even prized, a shade of colour is always detrimental.

In Nature, many minerals occur in a glassy clear condition, with fair crystal shape. These are attractive because of the brilliant flashes from the natural facets, and doubtless caught the attention of early man; but when, and where, it struck some individual to improve the natural faces, by polishing them to a greater extent than Nature had done, we do not know. It also seems to have been discovered at an early date that a facet perpendicular to a flaw minimised the effect of the reflection of light from the sides of that flaw, and these discoveries led to the display of the lapidary's skill in placing reflecting facets all over the surface of the gem, and thus adding to its beauty. But they did not lead at once to the development of the wonderful 'life' of the modern gem.

Now natural crystals usually occur with faces developed on one end and on the sides; therefore, although the faces reflect a good deal of light, the moiety that is refracted into the crystal, as a result of oblique incidence on these faces, is not returned to the surface to any extent; it passes into the matrix on which the crystal has grown. Indiscriminate setting of facets on a mineral, however, will have the effect that some of these faces will be nearly opposite others, and one could speak of a front and a back to the gem. At the front some light would be reflected, but some would also be refracted into the material, and, should this light impinge on the back facets within the angle of total reflection, it would be reflected inside the material and perhaps returned to, and emitted from, the front. Had such internally reflected light remained unchanged during its passage through the material, little notice would be given to it, but it has suffered dispersion into the prismatic colours of the rainbow, in addition to mere reflection from face to face.

But the older lapidaries covered the front of the gems with small facets to such an extent that little light actually entered the stone, and consequently the wonderful 'life' was rarely disclosed. Many of the diamonds of history were cut in this way, and they are, on the whole, duller and less interesting than they might have been. Of course, a minimum amount of material was used up during the processes of cutting and polishing by this method.

Probably the earliest step towards the modern ideal in cutting was taken by Lodewyk van Berguem about 1476. A descendant of his, writing in 1669, claimed that his ancestor had invented the process of cutting diamonds; but this is evidently erroneous, for there are records of a guild of diamond cutters in Burenberg so early as 1375. Van Berguem discovered that absolute svmmetrv in the arrangement of facets on a gem improved the general effect, and the pendeloque style of cutting is usually attributed to him. To-day we think this style rather dull, but it is certainly more attractive than the styles of the Oriental lapidary with their multitude of small facets arranged with scarcely any regard for symmetry.

Towards the middle of the sixteenth century another forward step was made and the rose-cut devised. Here a number of triangular facets are placed on the surface of the gem. The facets are usually triangular and equilateral in shape, but unless the stone is rather thick the 'life' of the gem is not really marked. All these methods of cutting were more concerned with economising material and hiding flaws than developing the full beauty of the gem.

Another century passed before Cardinal Mazarin suggested that the prismatic effects ('life') should be sought, rather than mere bright flashes from the surface faces, and he had certain diamonds re-cut by the lapidaries in order to secure such effects. The improvement was most marked and diamonds cut in this way were called 'mazarins' in honour of the discoverer. In this style of cutting the top facets were made rather larger than before, and the back faces arranged at fairly steep angles, and the absolute symmetry introduced by Van Berguem was retained. As a matter of fact, the natural octahedral faces of the crystal of diamond were made the basis of the shape, which was therefore rather square. Extra facets were made along the edges of the large natural faces of the crystals and so the gems were termed doublecut.

Peruzzi added still further to the number of facets, especially round the centre or girdle of the gem, and these were said to be triple-cut. The effects were striking and the style was known as the brilliant-cut. Compared with modern brilliants these were dull, though much brighter than the older styles. They were still too thick, and doubtless it was the desire to economise the material that prevented the attainment of the ideal beauty of the diamond. By reducing the angle between the black facets and the plane of the girdle-and incidentally losing more material-and altering the angle of the corner facets on these older styles of brilliants, a better effect was obtained. In the process the stone becomes rounder in shape, and, to-day, the best type of brilliant is the round form.

Tolkowski has shown recently, from theoretical considerations, that the angle of the back facets should be $48^{\circ} 52^{\prime}$. This would secure the greatest brilliance and 'life'. But a slight loss of brilliance is accompanied by added 'life', and, when the angle is $40^{\circ} 45^{\prime}$, the best all-round effect is attained. It is true that a great deal of material is lost in the process, and about 52 per cent of the original weight of material may be ground away. The older lapidaries simply dared not lose so much material, or their patrons would probably have accused them of pilfering. 
Recently fashion has been experimenting with straight line effects, and many diamonds have been re-cut in corresponding ways. The beauty is not the best attainable, but the effects are not so dull as in the older squarish styles, for no attempt is made deliberately to economise material. The style adopted is called the step- or trap-cut, a type very appropriate to coloured gems but not really inappropriate to uncoloured material. In fabricating individual specimens of diamond, there is a constant compromise between fashion, loss of material and perfection of effect; and, while the round brilliant is the best compromise between effect and loss of material, the dictates of fashion cannot be neglected.

On account of the high angle of total reflection in diamond, the return of almost all the refracted light by total reflection from the back can be secured by cutting a small number of facets on the back. The light so returned is also dispersed. But other clear gems have lower angles of total reflection, and consequently several series of facets must be placed on the back to secure the return to the front of an adequate amount of light. The facets must also be arranged at several different angles. Near the girdle the facets are steep and nearer the base they are set at flatter angles. As a consequence the facets are smaller.

In the zircon-cut (used in the case of the zircon gems) the style adopted is a close approximation to the brilliant, but there is an extra set of small faces alternating with the main back facets, and set round the central facet at the back. In other white gems several extra series must be introduced into the back to secure the maximum return of light by total reflection. The dispersion of light has also to be remembered, but the degree of dispersion is, in most cases, so slight, as compared with that in the diamond, that this property, is rarely considered. Brightness rather than 'life' is sought, and the cutting is arranged accordingly. The shape then is controlled by the original shape of the specimen and the formation of a bright sparkling gem with so little loss as possible. Consequently the shape on the back is terraced, each step a little flatter than the one above, and the style is termed step-or trap-cut (from the Scandinavian trappa, a step).

Among coloured gems there are three classes, those with one unvaried tint, those with pleochroism, and those that are coloured by the interference of light reflected from inclusions, or from thin films of different refractivity, in the interior.

In the first category the shape is arranged to permit the maximum of light to enter and to be emitted after total reflection from the back. To secure these two effects the facets on the front are made so large as possible, and those on the back arranged in tiers. The trap-cut is frequently used both on the front and on the back, especially to-day when straight-line effects are the fashion; but the front is often brilliant-cut, and the back either trap-cut or zircon-cut.
Should the colouring material be streaky the front is made parallel, or nearly parallel, to the streaks of pigment, and thus a uniform tint is imparted to the whole. If the colour be in patches the best effect is secured if the coloured patch is arranged near the centre of the back for, in that case, most of the refracted light will pass through the coloured patch either before or after, suffering total reflection at the back facets, and so a uniform colour will again be imparted to the light emergent at the front.

The colour in pleochroic minerals varies with direction, but one colour is more pleasing than any other, and the lapidary strives to retain that tint in the finished gem. The front is cut either trap or brilliant style, and set so that the central facet is perpendicular to the direction of best colour. The back is trap-cut, but it is elongated so that the facets across the direction of the least desirable colour are small and steep, and consequently return very little light to the front. The facets that cross the direction of good colour are made large, and at low angles, so as to reflect so much light as possible to the front. Sometimes a modified zircon-cut is used on the back with those facets across the direction of undesirable colour set at a steeper angle than the others. In this last case the whole gem has an elongated or cushion shape.

When the colour of the gem is due to the interference of light reflected from internal structuresinclusions or films of material of slightly varying chemical composition, and consequently with varying degrees of refraction of light-there is no necessity to place facets on the stone at various angles. The treatment is therefore similar to that of the opaque coloured stones, and large rounded surfaces are produced. In general, however, the surfaces are rather flat; bright flashes from these surfaces are not desired, the internal effects being those most wanted. The internal lights are best seen on flattish surfaces with rounded edges. Opal, sunstone, moonstone, labradorite are all of this type, and are translucent rather than opaque in character.

It must be conceded, therefore, that the fabrication of mineral species suitable for gem stones is a highly skilled operation, if the finest possible effects are to be obtained. The treatment, moreover, varies with different categories of mineral. Definite scientific laws must be obeyed, though the laws themselves have been arrived at empirically, and formulated, not in mathematical symbols, but by observation of the effects as the work proceeds. The work is initiated by the experience of the artificer of similar materials; lack of experience, so much as lack of skill, may render the final result unsatisfactory.

As the artist obeying certain laws, and by the skilful arrangement of his colours, may produce a beautiful picture, so the skilled lapidary, obeying the laws of optics, may transform a mere mass of mineral into a dazzling or a richly coloured gem. 